\title{
Social Prescribing the Smart City
}

\author{
Sonja Pedell \\ Centre for Design Innovation \\ Swinburne University of Technology \\ Australia \\ spedell@swinburne.edu.au
}

\author{
Ann Borda \\ Centre for the Digital Transformation of Health \\ University of Melbourne \\ Australia \\ aborda@unimelb.edu.au
}

\begin{abstract}
Our research explores the potential role of social prescribing in a smart city context positioned at the crossroads of digitally enabled health, community care and social engagement of older adults. Findings suggest social prescribing is ideally suited to be considered in an age-friendly smart city discussion on active aging.
\end{abstract}

Social prescribing. Smart cities. Wearables. Active ageing. Older adults.

\section{AGE-FRIENDY SMART CITIES AND SOCIAL PRESCRIBING}

This study explores thematic intersections of the World Health Organisation (WHO) programme "Age-Friendly Cities and Communities" and wearable health technology (WHO 2007; 2018). We bring together the two domains of "Communication and Information" and "Outdoor Spaces and Buildings" to create a convergent infrastructure that enables "Social Participation" a third domain named in the WHO framework (WHO 2018).

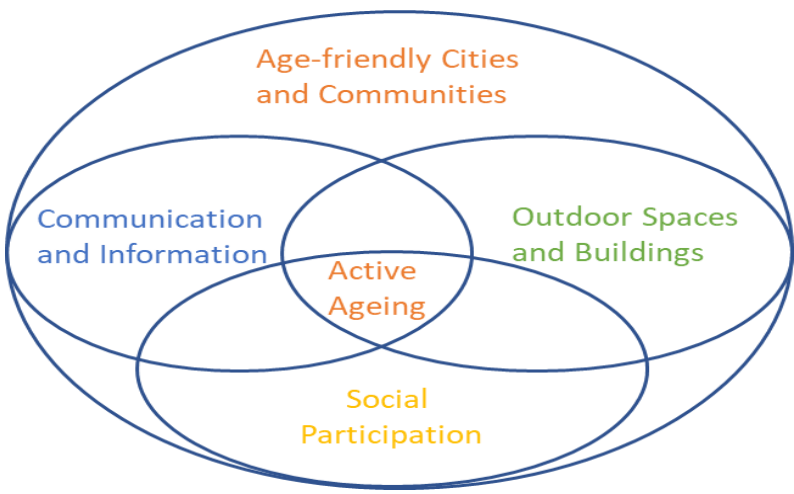

Figure 1: Convergence of Age friendly domains from: Pedell et al. (2021).

We see social participation within a broad remit in that actively engaging in the smart city environment and community spaces, e.g. parks and museums can facilitate social encounters and support the choice to socialise. Such participation can be effectively supported through social prescribing - a non-medical referral that links community services with people who are at risk, or experiencing isolation or depression (Carnes et al. 2017). Different types of social prescribing and related social participation initiatives are especially beneficial to older adults in which the world city populations aged 65 and over are expected to exponentially grow by 2050 (Ritchie \& Roser 2018).

Prescribed activities can fall broadly within 'social', 'physical' or 'economic' categories (Woodall et al. 2018) and aim to improve self-care within the community (Moffatt et al. 2017). Services often focus on improving mental health and physical wellbeing, for example, through volunteering, group learning, gardening, healthy eating advice and sports (Husk et al. 2019).

In this way, social prescribing is positioned at the crossroads of holistic health, community care and social engagement and ideally suited to be considered in an age-friendly smart city discussion with a focus on digital inclusion. Support for active participation of older adults in a smart city setting can be achieved, for instance, through the use of digital devices and activity tracking wearables (Borda et al. 2018). Such technology is being increasingly adopted by older adults and can lead to sustained independence and reduced risk of isolation in a smart city context on top of the current narrow functionality of the devices.

\section{APPROACH}

We explored the complex relationships between the age-friendly city domains and older adults conducting qualitative interviews and focus groups to gain an in-depth understanding. In all studies three thematic frames were applied to analyse the 
qualitative data in building an evidence base; namely the emotional, quality and functional goals of older adults' needs in regard to the age-friendly city domains (Pedell et al. 2021). Understanding the emotional goals was crucial to understand the needs and we see them to be key for planning for successful smart city solutions.

\section{FINDINGS FROM OUR RESEARCH}

For users of wearable technology in the local built environment it was identified that participants wanted to feel motivated, in addition to wearable devices aiding in the management of their wellbeing and to support physical activity and social interactions (Borda et al. 2018). While the potential design for future wearable devices can consider some of these goals, the built environment (or the lack of detailed knowledge about the environment) can still present barriers in achieving them (Pedell et al. 2020; 2021).

These barriers can be potentially addressed using open data applications; for example, an agefriendly smart city 'layer' might highlight facilities such as public toilets, water fountains, cafes and shaded rest stops located on exercise routes. Barcelona's smartappcity is one of a growing number of open apps which are integrating city services and urban plans. The rise of digital citizenship is further facilitating data collection and sharing in smart city environments (Reuter et al. 2020).

Our research showed that a large variety of active aging programs offered by city councils also need to be accessible through age-friendly infrastructure e.g. smart data about available parking or walkable pathways leading to venues) (Priday and Pedell 2020; Pedell et al. 2021). Similarly, senior citizens affected by loneliness can benefit from various social activities, but prescribed walking excursions often require support to access the over 700 listed activities in online platforms. In another case study in a local health council catchment we found that isolated older adults can experience social anxiety, or be fearful of new social environments (Pedell et al. 2020). Hence a first contact with new activity groups needs to be facilitated through a "warm handover" with a trustworthy person in the community, organised travel to the activity, and supported by trusted smart city information at each step.

\section{CONCLUSION}

Studies have identified that challenges can reside in socio-technical aspects, like digital literacy, access and usability of technology. It is the responsibility of government and communities to make sure that efforts for enabling active ageing in cities through digital platforms and wearables does not increase the digital divide and leave behind vulnerable user groups (OECD 2018). Efforts such as social prescribing could provide opportunities to be integrated in the wider objective of age-friendly cities instead of being considered as stand-alone services targeting isolated older adults.

The need for places and activities in these places where citizens, regardless of their age, will feel capable and safe across a range of experiences is a basis for re-thinking age-friendly and smart cities. This should be done collaboratively using participatory approaches with those affected in order to better enable them to achieve social participation and quality of life goals (Pedell et al. 2021; Reuter et al. 2020).

\section{ACKNOWLEDGEMENT}

Ann Borda received an Expert Visit grant in 2019 as part of the EU Horizon 2020 funded EPIC project. Sonja Pedell's research was partly funded by the ARC DP160104083

\section{REFERENCES}

Borda, A.; Gilbert, C.; Gray, K.; Prabhu, D. (2018) Consumer wearable information and health self management by older adults. In Studies in Health Technology and Informatics; Van den Berg, M., Maeder, A., Eds.; 246: 42-61.

Carnes, D., Sohanpal, R., Frostick, C., Hull, S., Mathur, R., Netuveli, G., Tong, J., Hutt, P. and Bertotti, M. (2017) The impact of a social prescribing service on patients in primary care: a mixed methods evaluation. BMC Health Services Research, 17(1).

Husk, K., Blockley, K., Lovell, R., et al. What approaches to social prescribing work, for whom, and in what circumstances? A realist review. Health Soc Care Community. 2020;28(2):309-324. doi:10.1111/hsc.12839

Moffatt, S., Steer, M., Lawson, S., Penn, L. and O'Brien, N. (2017) Link Worker social prescribing to improve health and well-being for people with long-term conditions: qualitative study of service user perceptions. BMJ Open, 7(7), p.e015203.

OECD. (2018) Bridging the Digital Gender Divide. Paris: OECD. http://www.oecd.org/digital/bridging-the-digitalgender-divide.pdf

Pedell, S., Borda, A. and Keirnan A. (2020) Social Prescribing in Australia: How the Bottom-up Model of Citizen Science Can Facilitate Stakeholder Engagement in Health Service Design. In Proceedings of DLLD 2020 p76-94. ISBN 9789464078923 (eBook). European Network of Living Labs (ENoLL).

Pedell, S., Borda, A. Keirnan, A., Aimers, N. (2021) Combining the Digital, Social and Physical Layer to Create Age-Friendly Cities and Communities. Int. J. Environ. Res. Public Health 18(1),325; 10.3390/ijerph18010325 
Priday, G., Pedell, S., (2020) Subverting the Narrative: Alternate Technology Approaches for Active Ageing, Information Technology Based Methods for Health Behaviours. A. J. Maeder, et al (eds.), pp. 61-76.

Reuter, A., Liddle, J., Scharf, T. (2020) Digitalising the Age-Friendly City: Insights from Participatory Action Research. Int. J. Environ. Res. Public Health 17: 8281; doi: $\underline{10.3390 / i j e r p h 17218281}$

Ritchie, H., Roser M. (2018) - Urbanization. Published online at OurWorldlnData.org. Retrieved from: https://ourworldindata.org/urbanization
Woodall, J., Trigwell, J., Bunyan, A., Raine, G., Eaton, V., Davis, J., Hancock, L., Cunningham, M. and Wilkinson, S. (2018). Understanding the effectiveness and mechanisms of a social prescribing service: a mixed method analysis. BMC Health Services Research, 18(1).

World Health Organisation. (2007) Global age-friendly cities: A guide. Retrieved from: https://www.who.int/ageing/ publications/Global age friendly cities Guide English.p $\underline{\mathrm{df}}$

World Health Organisation. (2018) WHO age-friendly environments programme. Retrieved from:

https://www.who.int/ageing/projects/age friendly cities $p$ rogramme/ 